\title{
ARSIS AND THESIS: A REVIEW OF TWO ELEMENTS OF RHYTHM IN NON-TRADITIONAL MUSIC WRITTEN BY F. H. SMITH VAN WAESBERGHE D.J
}

\author{
Sunarto \\ Department of Drama, Dance and Music, Faculty of Languages and Arts \\ Semarang State University, Indonesia \\ E-mail: 132233483@staff.unnes.ac.id
}

Received: December 2013. Accepted: Februari 2014. Published: Maret 2014

\begin{abstract}
This paper aims to discuss the comparative terms of arsis and thesis in the study of Western music. The purpose of the study is to study the forms of music from the terms of language and its application, because there are many elements of music that are not understandable. Method of this study uses classical literature and musicology approach in which the great phrase rhythm of Gregorian music was more appropriately take a literary term; arsis and thesis. The focus of this study is to discuss the terms of Arsis and Thesis used in the section of rhythm elements of nontraditional music. This study reveals several musical terms in which there are similarities and differences between the rhythm and bars of music. The similarities and differences in the analysis are based on the history of Western music from Gregorian music. Gregorian was monophonic music that still existed in Europe until the 19th century. There were only two phrases in Gregorian music; when the melody moved up and when it moved down. In this case, there were two main elements in Gregorian music; they were different in rhythmic and they were in one rhythm of music. Arsis is a hard melody while thesis is a soft melody. It could be said that arsis and thesis are also parts of the dynamics form of music work. Keywords: arsis; Thesis; music rhythm; nontraditional music.
\end{abstract}

(C) 2014 Sendratasik FBS UNNES

Keywords: arsis; thesis; music rhythm; non-traditional music

\section{INTRODUCTION}

In the first reunion of the alumnae of the Academy of Music Indonesia (AMI), the Chairman of the Academy asked us to prepare an article on non-traditional music. We decided to choose rhythm as the main discussion of the essay, because in our opinion, this is a very useful information, especially for music lovers. Rhythm can be considered as "the most basic element of music", according to D'Indy (D'indy, 1902, p. 2021). In addition, scientific discussions about the essence and embodiment of the music rhythm is not yet finished, so it is appropriate when Jaap Kunst begins his inquiries about bars of music and rhythms with a note: "There are no similar opinion from two experts of music theory about bars of music and rhythm ... This is the conclusion of the terms "rhythm" and "bars of music" (Kunst, 1950, p. 1). So, even though this essay discusses a rather abstract problem, it is still an actual problem today. It is really important for any music fan, both young generation and the older one.

These are the reasons why we choose 'Arsis' and 'Thesis' as the subject of this essay. We begin our investigation about the essence of rhythm and non-traditional mu- 
sic with a short division of the whole substance of this essay. At first we will conduct an analysis of the 'experience of rhythm in general' and 'experience of rhythm of the music' in specific. We focus primarily on the rhythm composition according to its concrete existence, including its all aspects. We call this rhythm as great rhythm, which exists in a whole music sentence.

The second analysis is about the composition of the macrocosm of 'entire music phrases' which consists of at least two basic parts, namely 'Arsis' and 'Thesis' which we will find a song, later, in the microcosm or 'concrete relation between tone and tone'. In this case, as a consequence of our investigation, we will explain the difference between small rhythm and arrangement of bars of music.

Finally, we hope that peole can make use this analysis to practice music lively, and then we reflexively focus on 'rhythm experience of the entire melody', both being played, or sung. As a consequence of the investigation, we cover the essay with the formulation of some basic theory about the rhythm of the music.

\section{Rhythm Experience}

We may not be able to experience the rhythm of the music in its purest state such as; when we are standing on the beach looking something that is called by Claude Debussy (1862-1918) in its composition La Mer: Jeux de Vagues, "waves play", it turns out that the ocean continuously moves characterized by the up-and-down movements. The term 'rhythm' in various foreign languages is based on the Greek verb, rheoo (Lidell and Scott, 1953, p. 1576), which means "to flow", then we can easily understand that by looking at the waves of the ocean, we can find some basic characteristics of rhythm.

But in that way, it has not been specifically described about rhythm as a subject matter of our investigation, namely rhythm and music. Rhythm in a state of a bit music as we see in the ocean waves and as also happens in music, for modern people, it's no longer experienced as a symptom of rhythm. Why? At least since the $15^{\text {th }}$ century, non-traditional music is no longer arranged according to the principles of rhythm, but it uses a different principle called 'bars' or "metrum", a Latin term meaning "count" (Lewis and Short, cabbage 1951, p. 1141 b). So, for a music fan of the 20th century, it is very difficult to imagine the rhythm of the music. In general, he focuses his attention on "bars of the music".

However, we can experience the rhythm of the music purely if we focus our attention on the beauty of its compositions within melody. For example, Aria from Suita D Major, an essay by JS. Bach, or Aria from Suita Holberg, written by Edvard Grieg. In fact, the most obvious example of the true music rhythms is found in vocal music for one sound only. We know that nontraditional European music evolved on the basis of vocal music that its aesthetic values are highly appreciated by famous composers, including Mozart (1756-1791) and Paul Hindemith (1895-1963). Whereas, the two composers lived different times and also compose the different style of music. So, as an example of a true music rhythm, we will analyze a sentence or phrase melody of Gregorian music (Plainsong), a single music in Europe until the 19th century.

As well as the rhythm experience of the ocean before, we find out that the rhythm of the Gregorian melody was apparently characterized by up-and-down movements, but the tone stream has a start and an end. Many Gregorian songs begin with a tone and rises to a peak of the tone; then goes down to the early tone, to put an end of the whole movement of the melody, as well as to achieve the aimed tone in recreating a calm atmosphere. Therefore, the classical structure of the Gregorian melodies reflects the same thing as the rhythm structure that we find in the previous ocean-rhythm analysis. We can distinguish two main parts on the phrase of Gregorian music: the first part is equal to the time when the waves move up, the second one is when the waves move down. In other words: there are two main elements which 
are different on rhythmic in the sentence of Gregorian classical music, and thus, both of those main elements form a movement of complete great rhythm. So, it's definitely right when the rhythm of great phrase of Gregorian music uses famous terms of classical literature, namely "Arsis" and "Thesis", moreover when these two Greek words are used according to the basic meaning, namely: ' lift 'and' put '(Lidell and Scott, 1953, p. $248 \mathrm{col}$ a and p. 794). In the rising part, the tones are rose to its peak, aren't they? And in the down part, the tones, as if, are put in a quiet place gent$l y$, aren't they? It's understandable that the music phrase also uses the terms "Arsis" and "Thesis". The "arsis" of melody does not only show a rising line movement, but they are also rather strong and somewhat short, especially when compared with the part of tension releasing of the melody, right? And vice versa, "Thesis" musical sentence: it does not only show a descending melodic line, but it is also a dynamic which reduces its power until it runs out, and takes more time than "Arsis", right?

Thus the macrocosm structure of the Gregorian melodies is arranged of at least two basic elements of rhythm, namely: "Arsis" and "Thesis". Both main elements of great rhythm is not only different on aspects of melody direction, but also on aspects of length and dynamics of both of the great rhythm.

When the conclusion about the arrangement of a great rhythm has been well received, we can begin the second phase of our investigation, namely the arrangement microcosm rhythm or "concrete relation between tone and tone" because the whole and the unity of the melody are valued higher than the refrective knowledge of small rhythm or microcosm. On the contrary, if there is no awareness and knowledge about small rhythm, people can't play music although the composers arrange it beautifully. Therefore we will explain that small rhythm also has the elements of "Arsis" and "Thesis", and compare this rhythm with "bars of music".

\section{Analysis of Small Rhythm}

The new stage of our investigation is a continuation and application of analysis conducted on a great rhythm before; then, we begin with some observations about the composition of the small rhythm of Gregorian music. Then we will complete this information with a little investigation on small rhythm of other music.

We need to discuss it first because of the assumption that small rhythm is based on tone in which its time can not be divided. In other words: an analysis of a small rhythm starts with the point of "atomic time" or the Greek term, prootos Chromos (Lidell and Scott, 1953, p. 2009, a cabbage), means 'time base' which underlies the whole system of music. Therefore, "small rhythm" can only be formed by adding at least two 'atomic time' or tone that can not be divided (Kunst, 1950, p. 9; Badings, 1959, p. 41; Hood, 1971, p. 35). In modern musicology, this rhythm is called additive rhythms' (Sum Rhythm) or synthetic rhythms (Rhythm which is used as one). Then it should be noted that small rhythm is different from rhythm, based on the tones that can be divided (into half, quarter, eighth, sixteenth, and so on).

This rhythm is called divisive rhythm, means that the rhythm with down distribution of rhythm, or also rhythm analytical, means: rhythm that needs to be investigated in details (Jaap Kunst, 1950, p. 8-9; Badings, 1959, p. 41; Hood, 1971, p. 35). As a conclusion of a small rhythm or synthetic rhythm based on the time which can not be divided (atomic time), should be noted here: it needs, at least, two time unitaries to form the simplest rhythm. Then the rhythm consists of two tones is called single binary rhythm, means "one second". When the rhythm consists of three basic unity of time, which is of the three tones, we use the term lineer single rhythm, means "one third".

We just talk about a small rhythm of Gregorian music in terms of length tones that forms melody. The composition of the macrocosm rhythm will be found in the microcosm rhythm or in the relationship 
between one tone and the next tone. It means that there are "Arsis" and "Thesis" in small rhythm, there is a rising melody movement which become stronger and faster, and then goes down to be slower and quieter. We receive this information from the founder of singing method of Gregorian, called "solemnes method", i.e. Dom Andre Mocquereau OSB (1849-1930). In the most basic time of "solemnes method", which is entitled Le Nombre Musical Gregorien (Tournai: Volume I, 1908; vol II, 1927) artists and music paleography experts explain, as follows:

1. True rhythm of movement always starts with an Arsis that is in the small rhythm ternary disobel, and ends with a Thesis that can never be disobel but can be followed by one Arsis again.

2. Arsis is always tense, on the other hand, Thesis is a relaxation.

3. Arsis is strong, means bre-cresendo; otherwise Thesis is soft or decrescendo.

4. Generally, Thesis needs more time than Arsis.

5. Arsis melody is called a tone when it is followed by a lower tone; the second tone is called Thesis melody.

It might be surprising that we do not find the terms "accent" or "pressure" in the whole description of Gregorian. The theories of Dom Mocquereau also uses the common terms, not technical terms, so it is rather difficult to understand the accents as found on other music that is not rhythmically free. Inspite of the lack of authentic information about the Solemnes method, we should remember that, at least, implicitly there is an accent on the Gregorian small rhythm. It is said that an Arsis is tense, strong, and shorter than a Thesis, then it can be called that this rhythm section is accented, without any danger of this pressure will be equated with other accents in the other music. Even the nature of the Gregorian accent becomes truly apparent, when someone plays the Gregorian melody, the Arsis melody is accompanied by Arsis dynamics. Thus, the structure of great rhythm movement is reflected perfectly in a small rhythm arrangement. To avoid misunderstanding about the type of accent here, it is better if we use the term of 'Arsis accent'. While accent which is discussed later in the rhythmical music is called "Thesis accent", Dom Moncquereau reveals specific characters of Arsis and Thesis in a small rhythm of Gregorian by giving the name 'elan' and "repos" which means (roughly) as "preparation move" and "peaceful" or "relaxation".

So far, we only talk about small rhythm in its simplest form, i.e. single rhythm, either binary or triner. The most important thing is the relationship between one small rhythm and another one, or rhythm compound (In French Dom Mocquereau use the term le rhyme compose) (1908, p. 80-90). We will limit our discussion on two principal aspects of this compound rhythm, which will be completed in the third section, and we will focus our attention on the rhythm experience of the melody.

1. It should be noted that the rhythm of melody also begins with an Arsis and ends with a Thesis.

2. The existence of 'Arsis' compound rhythm depends on the structure of the entire music sentence that can be divided into a number of small rhythms. Because there is a close relationship between the structure of melody and the composition of this compound rhythm, it's better to discuss the description of the more complex rhythms in the last part of this essay.

Before we focus on great rhythm, we need to check the small difference between small rhythm and bars of music. Bars of music begins in the Middle Age, becomes more powerful in music, so, it is easier for us to feel it than a small rhythm. To clarify the differences between small rhythm and bars of music, please pay attention to the meaning of the term bars of music or 'metrum': The Latin word metrum is based on the Greek word, metron, means: "size" or "count", right? "(Lidell and Scott, a cabbage 1953, p. 1123). It's different from the word "rhythm" which in Greek means "principle of movement" or "dynamic", the word 
'bars of music' expresses free principle and it's static. In addition, bars of music or count principle focus on the length of a tone and musical time, not on dynamics. In ancient times, the term "metrum" is used to set the classic poem, for example in Greek drama, sentences with short and long syllables must be arranged according to one of the "metron", line by line: long-short-shortlong-short-short, or short-long-short-long. In other words, previously, "metron" does not arrange stress or accent, but the time and the length of syllables. Therefore, it is natural that the term "metron" or "bars of music" is used to measure the time of music. And even on a rhythm system, that kind of measure can be very beneficial. Because the bars of music expresses the good order aspects in music, so this factor may be viewed as an expression of the human being in music, based on the body and especially on the soul (Badings, 1959, p. 41).

But if the principle of bars of music is previously used to organize and measure the length of the tones, this does not mean that there is no relationship between bars of music and stress or accent. In the development of music, bars of music also sets the tone accents, this can be seen in the lines of vertical bars which firstly appeared in the music manuscripts in the 15 th century. And the development of the main features of bars of music is also justified in various books of modern music theory, such as Emotion and meaning in Music, Written by Leonard B. Meyer (Chicago, 1965). It should be emphasized that the difference between the principle of bars of music and rhythms is on dynamics aspect. Indeed, bars of music are divided according to binary and ternary, as well as in a small rhythm. But, it needs to emphasize the difference between the two principles of music movement, they are: there is always a Thesis (not arsis) at the beginning of bars of music. The first blow of bars of music is always accented, and this accent is totally different from that of Arsis Greorgian music. It's just the same as the conductor gestures direct the first blow of bars of music downwards, so this is a bit heavy accent. The nature of Thesis accent is that it requires longer time than Arsis (Remember to number 4 on the description of the "Method Selomnes" earlier), this trait is strengthen when the first pitch is widened. In other words, both small rhythm and bar of music always begin with an accented tone: but those accents are truly different. The difference between these two types of accent is shown when a conductor gives command to Gregorian songs and to music of nonGregorian. We should remember the explanation in "Le Nombre Musical" about Gregorian music directors. In the second volume of article 13 and 14 Mocquereau explains special knowledge about Gregorion directors or cheironomi, means that the rule or the command by hand (Mocquereau, Volume II, 1927, p. 684-750).

We know that the hand command upwards is an expression of "arsis" which is important in Gregorion rhythm. Maybe the differences of Thesis accent and Arsis accent can also be seen in the dynamics embodiment which becomes refractive in a non-traditional music, since about 1750 . The dynamics of the baroque era is "register dynamic" which merely distinguishes between forte and piano. Moreover it begins with the German style of music called "School Manhheim", this register dynamics is replaced with "transitional dynamics". Since the Romatik times then, people have been accustomed to an embodiment of the dynamics of music which is really not static anymore, but obviously is dynamic, means: the nature becomes a little bit hard from piano to forte, and conversely it softens from forte to piano. If someone wants to use the 'Thesis' accent to reveal the modern dynamics, the Thesis accent should include a small and short decressendo. On the other hand, Arsis accent needs to express a Cressendo. Kunst (Kunst, 1950, p. $8)$, wrote that he had read a surprising sentence in Handbook of Harmony, that is: Arsis is also alled Thesis, and Kunst continued his writing: "The author does not capture the ultimate meaning of these terms." So, in the same essay, Jaap Kunst explained: "Arsis and Thesis are opposites in essen- 
ce "(1950, p. 8). However, this does not mean that rhythm and bars of music are opposites! People emphasize the differences between the two elements of the melodic movement, both of this music factors are completed and strengthen to each other. Although Arsis and Thesis have different accent, even in free rhythm, such as in Gregorian music, it doesn't need to refuse bars of music factor. In the last number of this essay, we will discuss free rhythm which can be accompanied by the composition of free "bars of music". Meyer, as quoted above, inserts a selection of five types of bars of music which is used in ancient times to prepare the Greco-Roman classical poetry. These five types of bars of music is used to describe the structure of the simplest rhythms and bars of music (Mocquereau, Volume II, 1927, p. 1-40; Howeler, 1952, p. 154-157 (+ Table II: Lengte en sterkte metra); Meyer, 1965, p. 103).

This is a conclusion of the difference between rhythm and bars of music that can be formulated as follows:

Bars of music can only be aranged by binary or ternary bars:

$\begin{array}{ll}\text { trochaeus } & \text { : Long-short } \\ \text { dactylus } & \text { : Long-short-short } \\ \text { jambe } & : \text { Short-Long } \\ \text { anapaestus } & \text { : short-short-long } \\ \text { amphibrachus } & \text { : Short-long-short }\end{array}$

We still need to discuss the difference between accents of 'Arsis' and 'Thesis' before we close the chapter on a microcosm of small rhythm, particularly the problem of the difference between small rhythm and bars of music composition. When a person wants to summarize the entire history of rhythm development of non-traditional music, it will be strictly distinguished into three stages, namely:

1. Free rhythm (in Georgian music)

2. A rhythm called "flying rhythm" (in classical polyphone music). There will be an explanation about the difference between Arsis accent and Thesis accent),

3. The rhythm is bound to the same bar of music.

The second rhythm, flying rhythm, is a privilege of polyphone music of the 16th century. Its specific is that the first blow of bar of music does not occur at the same time for each sound, so, sometimes the rhythm seems a true poly-metric (Kempers, 19479091). The problem of rhythm of the music of the Middle Ages which was not monophon but true polyphone, was getting difficult because people generally assume that the accent should occur on Thesis only. Therefore, the Thesis accent is often said to be occured in a heavy rhythm section. But, historically, the music of the Middle Ages is directly based on the free rhythm of Georgian music, so, it is not surprising that the 'Arsis' accent also often play an important role, in other words: it's not true if the compositions of flying rhythm are added with the lines of bars of music (which at first did not exist in Middle Age manuscripts). Due to the presence of bars line, the first sign in each bars of music is called tactus means "touch". This kind of interpretation is developed when polyphone music is replaced by a new musical style, that is 'monodi'. Thus, the term "flying rhythm " is often equipped with the term "freely", to express clearly that the rhythm of the monophon Middle Age music, i.e. "free rhythm", is different from a rhythm that is bound to a fixed bars of music system.

Then we will discuss about the description of the great rhythm and melody. Synthetically, we get closer to the great rhythm of the melody, based on small rhythm analysis

\section{Experience of Synthetic-Reflexive Great Rhythm}

As stated at the beginning of this essay, the analysis of the second part are rather abstract and is only intended as a principle; then as the third step, it needs the analysis results of small rhythm to be confronted with a practice of live music. Indeed, people of the 20th century are accustomed to experiencing great rhythm structures by bars of music. Then the description of the third part will justify the practice of music. It is stated earlier that both rhythm and bars of music are different but they are complete each other, right? 
This assumption is very clearly stated by Meyer in his book. Meyer, a professor of music from Chicago University, explains how the same bars of music, for example in three quarters, can be used in a variety of different rhythms! Menuetto of the first Simfoni composed by Beethoven uses a very clear melody, that is jemble rhythm (short-long), while Menuetto of Symphony no. 94, composed by Haydn (mit dem Paukenschlag or "by surprise"), uses a melody with amphibrachis rhythm (short-longshort). Though this Menuetto is based on the classical bars of music for Menuetto, that is three-quarters, but we can see in the second example that there is a composition of melody, which change its rhythm started on the third amphibrachus, and suddenly it's replaced by jemble rhythm (short-long) which is added with anapaestus (short-short-long). These examples prove, that freedom of rhythm and the accuracy of bars of music strengthen the beauty of the synThesis of the two factors of this music, it means, it does not interfere each other.

According to Ir. H.H. Badings in his book Charles Lalo: Elements d'une Eshetique Musicale Scientifique, one person might be more interested in a clear metrum, as we find in music with a rather freely rhythm, as the tendency of the romantic era music. But the tastes just show anaccidental differences in the actual assessment. In other words, the tastes differences show a different accent, not an absolute contradiction. In terms of its efforts to complete and to balance each other, it can be justified that the classical definition from the fourth century BC, that is: "Rhythm is flowing bars of music; bars of music is a rhythm that is tied to a particular form" Thus: Flavius Sosipater Charisius in his essay: Ars grammatica, means: grammatical science.

To achieve the purpose of balance, both small rhythm and bars of music should play role seriously in the whole melody. In other words, the basic elements of music should participate as a composition factor in the establishment of great rhythm of the whole melody. It may be said that bars of music and small rhythms contain only the materials, which must be souled and brought to life by melody! This is why the famous conductors pay special attention on the structure of the melody as a whole, taking into account the whole 'Arsis' and 'Thesis' either harmonious or agogis. Related to this fact, I remember an interview of the conductor of the orchestra "Concertgebouw Amsterdam", Eduard van Beinum, when he was pointed as the orchestra conductor. To the question: Which principle do you take to conduct the orchestra, he answered: "I heard the composition of the melody to be played, and that melody becomes the inspiration to conduct any orchestra". The awards of high melody is also found on the famous Switszerland conductor, Ernest Ansermet, who was in an international meeting between artists in the city of Geneva in 1948 states the following: "The melody was not only the first factor for the music to be occur, but rather a natural event inside that is continually occur", a statement that is asserted in the book Acrits sur la Musique (Neuchatel (Switzerland), A la Bocanniere. However, small rhythms and bars of music can not be souled fully and deeply, though it is aided by its melody as a whole, if the rhythm and bars of music are not meant as 'Arsis' and 'Thesis'. It is important to notice the distinction and the comparison between the two levels of the music, which is at a basic level or a microcosm of rhythm, as well as the whole melody. Both levels are not separate reality. Both levels are new patterns that would reveal the full ability, when seriously considered both the melody as a whole, as well as all the elements of rhythm and bars of music inside it, based on a careful analysis.

Based on this conviction, and especially descriptions we provide in section IV of this essay, it is time to end the investigation of the essence 'Arsis' and 'Thesis' in the field of non-traditional music bygiving some statements as follows:

each tone in a particular melody is already 'Thesis' or 'Arsis'!

a particular tone can get a 'Thesis' 
accent, for example, if it occurs on the first count in the bars of music; and it gets an 'arsis' accent, if it occurs on an even count in bars of music; therefore, on the ground level, there might not be two 'Thesis' follow each other directly; it always needs to be punctuated alternately at least by one 'Arsis'.

'Arsis' is always typically characterized by an upward movement of the hands, which are lightweight, short, strong, and usually performed with Cressendo. 'Thesis' is always characterized typically by a downward movement of the hand that is heavy, long, hard, and usually performed with decressendo.

\section{CLOSING}

This is the end of our investigation of the essence of 'Arsis' and 'Thesis' as the elements of the rhythm in non-traditional music. We are aware that many problems that are closely related to this issue, now can only be touched. For example, Dr. F.A. Steinhausen: in Die Physiologe der Bogenfuhrung have viewed how 'Arsis' and 'Thesis' is influenced by the vertical harmony. Or: does the information of Solemnes method about small rhythm pay enough attention to the balance between 'Arsis' and 'Thesis'? Or: do 'Arsis' and 'Thesis' as described earlier was parallel to how to play the violin with up and down friction?

Actually these kinds of problems are closely related to the subject of this essay investigation. However, in this reunion, it would be wise, if the material is restricted to this subject, because those problems can not be solved only with the few words. Perhaps there is a doubt about the benefits of such a vast writing of rhythm in monophon music (= with one voice) of the Middle Ages. But in this case we can quote Prof. Mantle Hood who assess monophon music of Middle Age as higher than the rhythmic music 'divisit' as found in all Western music since the Renaissance. The reason is because the monophon music plays role as an educational tool to be 'sensitive to the time'.

Inspite of the weakness of this essay, we restrict ourselves to a particular issue in a non-traditional music. We hope that this essay becomes a small contribution to the success of this reunion. And we truly support this activities.

\section{REFERENCES}

Ansermet, E. (1971) Acrits sur la Musique, Neuchatel (Switzerland): A la Bocanniere.

Badings, H.H. (1959) "Rhythm, Tempo en Metrum", in Encyclopedie van de muziek,Volume II, Amsterdam, Elsevier.

Charisius, F.S. "Ars Grammatica", in M. Cary CS, (1953), The Oxford Classical Dictionary, Oxford: Clarendon Press, p. $184 \mathrm{col}$ a.

D'Indy, V. (1902). Cours de Composition Musicale. Paris: Durand.

Hood, M. (1971). The Ethnomucicologist, New York: McGraw-Hill Book Company.

Howeler, C. (1952). Rhythm in Vers en muziek, The Hague: Mouton \& Co.

Kempers, B. (1947). Muziekgeschiedenis, Rotterdam, Brussels: MIY Uitgevers.

Kunst. J. (1950). Metro, Rhythm, Multi-Part Music, Leiden: E.J.Brill.

Lewis, C.T. \& Short, C. (1951). A Latin Dictionary. Oxford: Clarendon Press.

Lidell, H.G. \& Scott, R. (1953). A GreekEnglish Lexicon. Oxford: Clarendon Press.

Meyer, L.B. (1965). Emotion and Meaning in Music. Chicago: University of Chicago Press.

Mocquereau, D.A. (1908) Le Nombre Musical, Volume I. Tournai: Desclee \& Cie.

Steinhausen, F.A. (1920) Die Physiologe der Bogenfuhrung. Leipzig: Breitkopf \& Hartel. 